\title{
Enzymatic Intra- and Intermolecular Hydroalkylations of Alkenes through Ground-State Electron Transfer
}

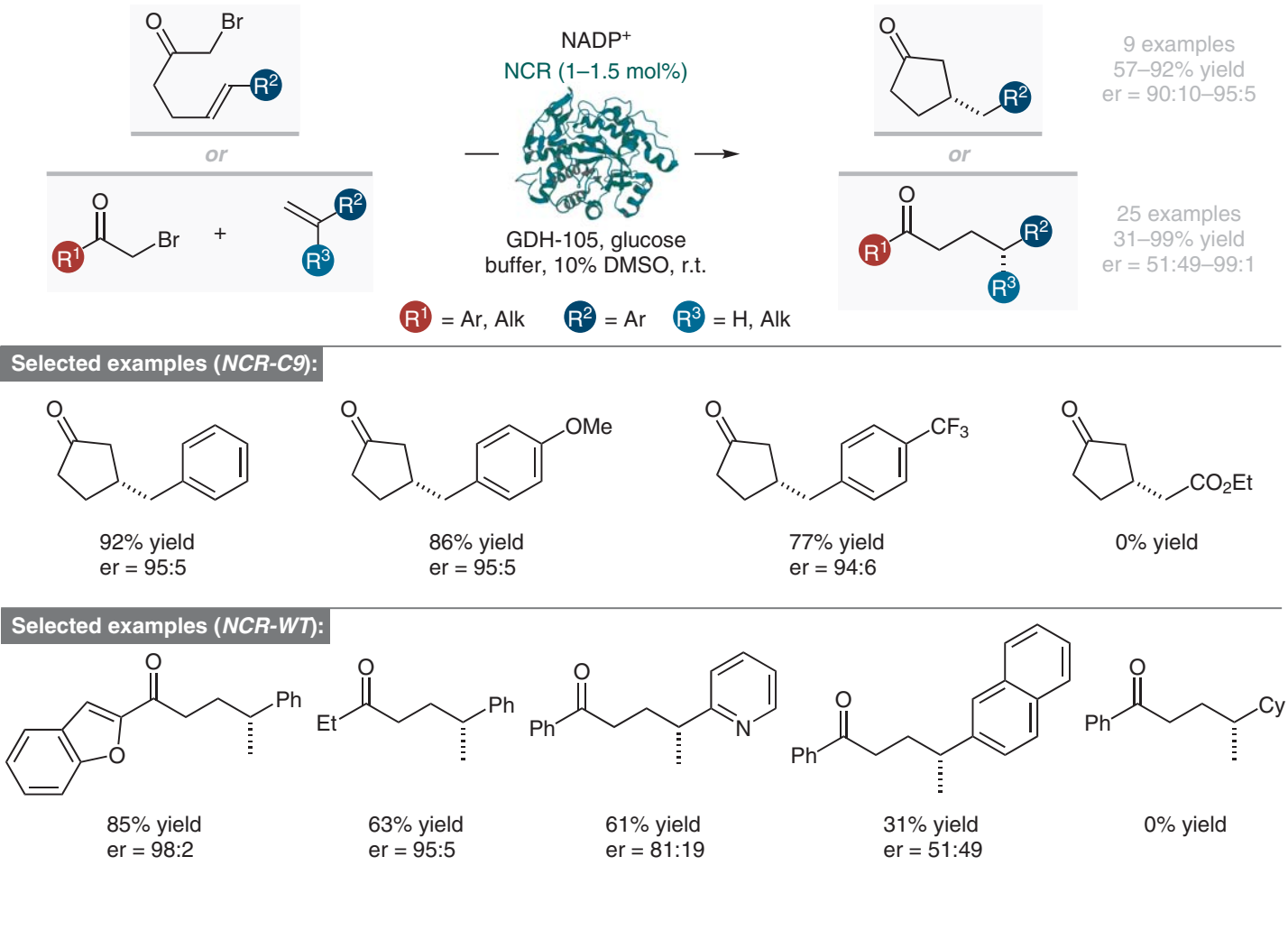

Significance: Hyster and co-workers report intraand intermolecular reductive hydroalkylations of aromatic olefins to form cyclopentanones or linear ketones in excellent yields and enantioselectivities. Quadruply mutated or wild-type nicotinamidedependent cyclohexanone reductase (NCR), respectively, serve as efficient biocatalysts. Starting from $\alpha$-bromo ketones, ground-state electron transfer from a flavinmononucleotide generates a ketyl radical that, through mesolytic $\mathrm{C}-\mathrm{Br}$ bond cleavage, generates the reactive $\alpha$-ketonyl radical. Notably, whereas the stereocenter in the cyclization reaction is set in the $\mathrm{C}-\mathrm{C}$ bond-forming step, the enantiocontrol in intermolecular reactions originates from a stereoselective radical-terminating hydrogenatom transfer.
Comment: Flavin-dependent ene-reductases (EREDs) have been previously applied in photoenzymatic settings (see, for example: K. F.

Biegasiewicz et al. Science 2019, 364, 1166). Whereas those reactions rely on the photoexcitation of a charge-transfer complex between enzyme, cofactor, and substrates, the analogous ground-state electron transfer had not previously been utilized as an initiation mechanism in $\mathrm{C}-\mathrm{C}$ bond-forming reactions. The authors therefore selected $\alpha$-bromo ketones as substrates due to their relatively high reduction potential, rendering ground-state reactivity kinetically feasible. Although the present method is an impressive example of enantiocontrol over real radical intermediates, the extension to less-stabilized nonaromatic substrates represents a considerable challenge for future research.

\section{Category}

Organo- and

Biocatalysis

Key words

hydroalkylation

alkenes

reductase

ground-state electron transfer

ketones 